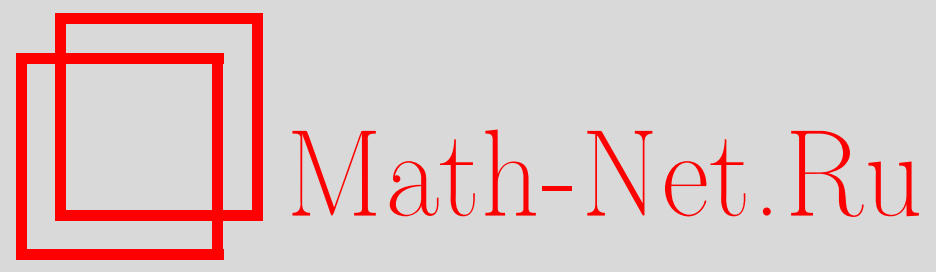

С. В. Горбунов, Экспериментальная проверка реологической модели разупрочняющейся вязкоупругой среды с экспоненциальным ядром ползучести, Вестн. Сам. гос. техн. ун-та. Сер. Физ.-мат. науки, 2012, выпуск 3(), 196-198

DOI: https://doi.org/10.14498/vsgtu1084

Использование Общероссийского математического портала Math-Net.Ru подразумевает, что вы прочитали и согласны с пользовательским соглашением

http://www . mathnet.ru/rus/agreement

Параметры загрузки:

IP : 54.196 .121 .252

26 апреля 2023 г., 15:50:12

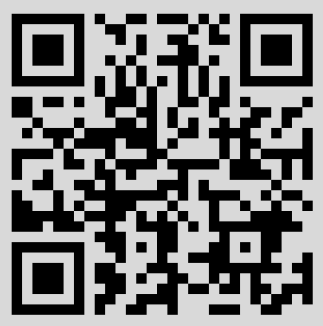


Вестн. Сам. гос. техн. ун-та. Сер. Физ.-мат. науки. 2012. № 3 (28). С. $196-198$

УДК 539.376

\title{
ЭКСПЕРИМЕНТАЛЬНАЯ ПРОВЕРКА РЕОЛОГИЧЕСКОЙ МОДЕЛИ РАЗУПРОЧНЯЮШЕЙСЯ ВЯЗКОУПРУГОЙ СРЕДЫ С ЭКСПОНЕНЦИАЛЬНЫМ ЯДРОМ ПОЛЗУЧЕСТИ
}

\author{
С. В. Горбунов \\ Самарский государственный технический университет, \\ 443100, Россия, Самара, ул. Молодогвардейская, 244. \\ E-mail: 4cepega@gmail.com
}

\begin{abstract}
С помощъю соотношений реологической модели вязкоупругой средъ, предусматривающей учёт эффектов разупрочнения материала, описано поведение древесного пластика ДСП-Г. Найдено значение предела длительного сопротивления материала, соответствующего границе устойчивого (асимптотически ограниченная ползучесть) и неустойчивого (появление третъей стадии ползучести) деформирования. Выполнено сравнение расчётных и эксперименталъных данных по ползучести и данных по пределу длительного сопротивления. Наблюдается соответствие расчётных и экспериментальных данных.
\end{abstract}

Ключевые слова: вязкоупругий материал, ядро ползучести экспоненииалъного вида, устойчивость дебормирования, третъя стадия ползучести, древесный пластик, экспериментальная проверка.

1. Из всех известных сегодня материалов можно выделить класс тех, для которых существует особая характеристика: напряжение $\sigma_{\text {пдс }}$, называемое пределом длительного сопротивления и определяемое экспериментально для каждой конкретной среды и внешних условий. При постоянной во времени нагрузке рассматриваемые материалы в условиях одноосного напряжённого состояния проявляют следующее поведение. Если значение приложенного напряжения меньше $\sigma_{\text {пдс }}$, то вязкоупругая деформация является ограниченной и асимптотически затухающей во времени $($ при $t \rightarrow \infty)$; разрушения образца не происходит, а при полной разгрузке наблюдается полная обратимость деформации. В случае, если напряжение превышает $\sigma_{\text {пдс }}$, появляется стадия ускоренной ползучести, которая заканчивается разрушением образца. К описанным материалам можно отнести стеклотекстолиты, органопластики, полимеры, биоматериалы. Приведённое явление вязкоупругости для перечисленных сред отличается от реологического поведения металлических материалов и требует собственного математического описания. Для этой цели в работе [1] были предложены базирующиеся на построенной в [2] теории неполной обратимости деформации ползучести следующие одномерные уравнения состояния:

$$
\begin{gathered}
p(t)=\sum_{i=1}^{k} p_{i}(t), \quad \dot{p}_{i}(t)=\lambda_{i}\left(a_{i}\left(\sigma / \sigma^{*}\right)^{m}-p_{i}(t)\right), \\
\sigma=\sigma_{0}(1+\omega), \quad \dot{\omega}=\alpha \sigma \dot{p} .
\end{gathered}
$$

Здесь $p(t)$ - деформация ползучести, $p_{i}(t)$ - компоненты деформации ползучести, $\sigma_{0}$ - номинальное напряжение, $\sigma$ - истинное напряжение, $\omega$ - скалярный параметр повреждённости, $\lambda_{i}, a_{i}, m, \alpha, \sigma^{*}$ - константы модели, которые определяются на основании экспериментальных кривых ползучести при $\sigma_{0}=$ const. B некоторых случаях уместно использовать аппроксимацию

$$
\alpha=\alpha_{1}\left(\sigma_{0}\right)^{n} .
$$

В работе [3] осуществлена попытка описать отмеченное выше поведение материалов с позиции устойчивости процесса деформирования. Исследование на устойчивость в смысле Ляпунова системы дифференциальных уравнений (1) в случае двух

Сергей Владимирович Горбунов, аспирант, кафедра прикладной математики и информатики. 
экспоненциальных слагаемых $(k=2)$ позволило получить критерий асимптотической устойчивости относительно напряжения $\sigma_{0}$, причём это напряжение и можно считать пределом длительного сопротивления $\sigma_{\text {пдс. }}$ С другой стороны, в работе [1] система уравнений (1) исследована численно, методом Эйлера («шагами» по времени), и установлено, что существует значение $\sigma_{0}=\sigma_{\text {пдс }}$ такое, что при $\sigma_{0}<\sigma_{\text {пдс }}$ численный метод сходится (имеем асимптотически затухающую ползучесть), а при

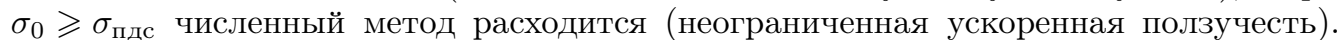
При этом получено, что значение $\sigma_{\text {пдс }}$, рассчитанное на основании численного решения системы (1) методом Эйлера, практически совпадает со значением $\sigma_{\text {пдс }}$, полученным по методу Ляпунова. Таким образом, работами $[1,3]$ установлена прямая связь между устойчивостью решений системы (1) и устойчивостью численных методов решения этой системы, а появление стадии ускоренной ползучести связано с нарушением условий устойчивого деформирования и потерей устойчивости (расходимостью) численного алгоритма. Целью настоящей работы является экспериментальная проверка предложенной модели (1) и выведенного критерия потери устойчивости деформирования.

2. Результаты экспериментов на сжатие вдоль слоёв шпона вдоль волокон рубашки древесного пластика ДСП-Г при температуре $20^{\circ} \mathrm{C}$ были заимствованы из [4]. В процессе определения констант модели (1) для рассматриваемого материала было установлено, что его поведение следует описывать с помощью двух экспоненциальных слагаемых $(k=2)$. Получены следующие значения параметров: $a_{1}=4,87 \cdot 10^{-3}$, $a_{2}=2,02 \cdot 10^{-3}, \lambda_{1}=0,033, \lambda_{2}=0,076, m=0,39, \alpha_{1}=0,112, n=-2.48 \cdot 10^{-4}, \sigma^{*}=$ $=350$ МПа. Система (1) решалась численно методом Эйлера («шагами» по времени) при следующих значениях напряжения $\sigma_{0}: 36$ МПа, 71 МПа, 82 МПа, 112 МПа. Результаты расчётов (штриховые линии) представлены на рисунке. Можно видеть, что наблюдается удовлетворительное соответствие расчётных и экспериментальных данных.

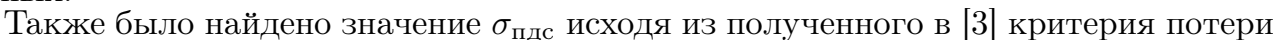
устойчивости деформирования, который для случая использования аппроксимации (2) принимает вид

$$
\begin{aligned}
& \left(\sigma_{\text {пдс }}\right)^{n+1} p^{0}=\left(\alpha_{1} m\right)^{-1}, \\
& p^{0}=\left(a_{1}+a_{2}\right)\left(\sigma_{\text {пдс }} / \sigma^{*}\right)^{m} \exp \left(\alpha \sigma_{\text {пдс }} m p^{0}\right),
\end{aligned}
$$

где $p_{0}$ - установившееся движение (здесь - асимптотическое значение деформации ползучести, соответствующее напряжению $\left.\sigma_{\text {пдс }}\right)$.

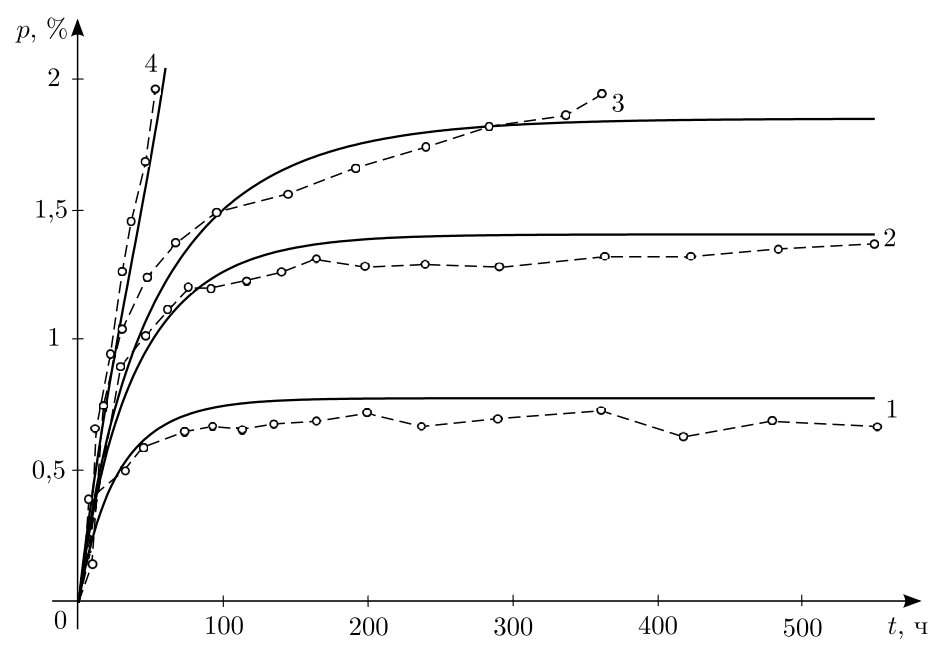

Расчётные (сплошные линии) и экспериментальные (штриховые линии) [4] кривые ползучести древесного пластика ДСП-Г при постоянных напряжениях: $1-\sigma_{0}=36$ МПа, $2-\sigma_{0}=71 \mathrm{M} \Pi \mathrm{a}, 3-\sigma_{0}=82 \mathrm{M \Pi а}, 4-\sigma_{0}=112 \mathrm{M \Pi а}$ 
При расчёте по аналитическому критерию устойчивости (3) было получено значение $\sigma_{\text {пдс }}^{\text {расч }}=82$ МПа, при численном расчёте методом Эйлера расходимость итерационной процедуры наблюдалась при $\sigma_{\text {писл }}^{\text {члс }}=80,3$ МПа; согласно экспериментальным данным $\sigma_{\text {пдс }}^{\text {экс }}=76 \pm 6 \mathrm{M \Pi а} \mathrm{[4].}$

\section{БИБЛИОГРАФИЧЕСКИЙ СПИСОК}

1. Горбунов C.В. Влияние эффекта разрушения материала на условия разупрочнения/ В сб.: Труды восъмой Всероссийской научной конферениии с международным участием. Часть 1: Математические модели механики, прочности и надёжности элементов конструкций / Матем. моделирование и краев. задачи. Самара: СамГТУ, 2011. С. 8186. [Gorbunov S. V. Method of determining parameters of the model describing creep and softening of viscoelastic materials/ In: Proceedings of the Eighth All-Russian Scientific Conference with international participation. Part 1 / Matem. Mod. Kraev. Zadachi. Samara: Samara State Technical Univ., 2011. Pp. 81-86].

2. Радченко В.П., Еремин Ю.А. Реологическое деформирование материалов и элементов конструкций. М.: Машиностроение-1, 2004. 264 с. [Radchenko V.P., Eremin Yu.A. Rheological Deformation and Failure of Materials and Structural Elements. Moscow: Mashinostroenie-1, 2004. 264 pp.]

3. Горбунов С.В. Математическая модель вязкоупругого разупрочняющегося материала с экспоненциальным ядром ползучести // Вестн. Сам. гос. техн. ун-та. Сер. Физ.мат. науки, 2012. №1(26). C. 150-156. [Gorbunov S. V. Mathematical model of viscoelastic softening material with exponential creep kernel// Vestn. Samar. Gos. Tekhn. Univ. Ser. Fiz.-Mat. Nauki, 2012. no. 1(26). Pp. 150-156].

4. Белянкин Ф. П., Яценко В.Ф., Дъбенко Г.И. Прочность и деформативность слоистых пластиков. К.: Наукова думка, 1964. 218 с. [Belyankin F. P., Yatsenko V. F., Dybenko G. I. Strength and Deformation Capacity of Layered Plastics. Kiev: Naukova Dumka, 1964. 218 pp.]

Поступила в редакцию 18/V/2012;

в окончательном варианте - 10/VII/2012.

MSC: 74G55; 74Cxx

\section{EXPERIMENTAL PROOF OF THE RHEOLOGICAL MODEL OF VISCOELASTIC SOFTENING MEDIUM WITH EXPONENTIAL CREEP KERNEL}

\section{S. V. Gorbunov}

Samara State Technical University,

244, Molodogvardeyskaya st., Samara, 443100, Russia.

E-mail: 4cepega@gmail.com

Behavior of densified laminated wood DSP-G is described by relations of rheological model of viscoelastic medium providing consideration of effects of material softening. Value of material's long-term strength limit corresponding to boundary between domains of stable (asymptotically limited creep) and unstable (development of tertiary creep) deformation is found. Comparison of calculated and experimental creep data and long-term strength limit data is executed. Correlation between calculated and experimental data is observed.

Key words: viscoelastic material, exponential creep kernel, deformation stability, tertiary creep, densified laminated wood, experimental proof.

Original article submitted $18 / \mathrm{V} / 2012$; revision submitted 10/VII/2012.

Sergey V. Gorbunov, Postgraduate Student, Dept. of Applied Mathematics \& Computer Science. 